\title{
Real-time tracking of delayed-onset cellular apoptosis induced by intracellular magnetic hyperthermia
}

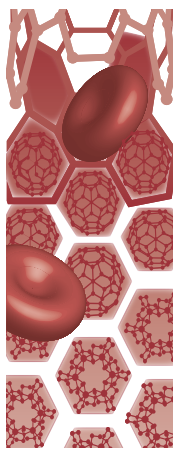

\begin{abstract}
Aim: To assess cell death pathways in response to magnetic hyperthermia. Materials \& methods: Human melanoma cells were loaded with citric acid-coated iron-oxide nanoparticles, and subjected to a time-varying magnetic field. Pathways were monitored in vitro in suspensions and in situ in monolayers using fluorophores to report on early-stage apoptosis and late-stage apoptosis and/or necrosis. Results: Delayed-onset effects were observed, with a rate and extent proportional to the thermal-load-per-cell. At moderate loads, membranal internal-to-external lipid exchange preceded rupture and death by a few hours (the timeline varying cellto-cell), without any measurable change in the local environment temperature. Conclusion: Our observations support the proposition that intracellular heating may be a viable, controllable and nonaggressive in vivo treatment for human pathological conditions.
\end{abstract}

First draft submitted: 01 August 2015; Article accepted for publication: 12 October 2015; Published online: 11 December 2015

Keywords: apoptosis $\bullet$ cell death pathways $\bullet$ human melanoma cells $\bullet$ magnetic hyperthermia $\bullet$ magnetic nanoparticles

Over the last decade the possible therapeutic use of heat generated in magnetic nanoparticles by time-varying magnetic fields, viz. magnetic field hyperthermia $(\mathrm{MFH})$, has been a subject of great interest in both the scientific and medical research communities [1-4]. The underlying principle is attractive and straightforward: that cancer cells are sensitive to elevated temperatures, and that in vivo treatments can utilize targeted magnetic nanoparticles to transform hysteretic energy losses, induced by the time-varying field, into a localized source of heat.

However, there is a significant issue with current translational research efforts in magnetic hyperthermia, in that the nature of the cell death pathways - as opposed to outcomes - that are triggered by MFH have until now been unclear. This is because almost all previously reported in vitro and/or ex vivo assays have relied exclusively on post hoc assessments of cell viability or morphology, as determined after the application of the time-varying field [5-11]. To our knowledge, the only exception to this rule, to date, was a very recent publication on real-time imaging of $\mathrm{MFH}$ experiments using a confocal microscope [12] - albeit that the focus of that work was on the immediate consequences of the $\mathrm{MFH}$ during treatment, and on lysosome membrane permeabilization events, rather than on longer term consequences to the cell as a whole. Furthermore, in vivo measurements of cellular function at the necessary subcellular length scale, and over the requisite period of time both during and after the application of the time-varying field, are not feasible in any approvable preclinical study. As such, the cell death pathways have remained an open question.

This issue is potentially a significant impediment in the clinical exploration of
Cristina Blanco-Andujar ${ }^{\ddagger 1,2}$, Daniel Ortega ${ }^{\ddagger 1,1,3,4}$, Paul Southern ${ }^{\ddagger 1}$, Stephen A Nesbitt ${ }^{1}$, Nguyễn Thị Kim Thanh ${ }^{* 1,5}$ \& Quentin A Pankhurst**,1

'Healthcare Biomagnetics Laboratory, University College London, 21 Albemarle Street, London, W1S 4BS, UK

${ }^{2}$ Institut de Physique et Chimie des Matériaux de Strasbourg (IPCMS), UMR7504 CNRS-Université de Strasbourg, 23 rue du Loess, BP 4367034 Strasbourg Cedex 2, France

${ }^{3}$ Instituto Madrileño de Estudios Avanzados en Nanociencia (IMDEANanociencia), Cantoblanco 28049, Madrid, Spain

${ }^{4}$ Nanobiotecnología (IMDEA-

Nanociencia), Unidad Asociada al Centro Nacional de Biotecnología (CSIC), Cantoblanco 28049, Madrid, Spain ${ }^{5}$ Biophysics Group, Department of Physics \& Astronomy, University College London, Gower Street, London, WC1E 6BT, UK

*Author for correspondence: ntk.thanh@ucl.ac.uk

**Author for correspondence: q.pankhurst@ucl.ac.uk

${ }^{\ddagger}$ Authors contributed equally 
$\mathrm{MFH}$, given that national health authorities and regulators around the world are almost always concerned to understand the 'primary mode of action' of any given intervention. In the case of MFH, this translates into a demand for a comprehensive model, at the cellular and subcellular level, of how the localized generation of heat affects the tissue and fluid environment in which the magnetic particles reside. In particular, there are fundamental questions to be answered as to whether the primary mode of action is a purely physical one, or one that involves an induced biological response. In many countries this can determine whether or not the intervention is classified as that of a medical device (e.g., in the case of a physical mode of action), or that of a drug (e.g., in the case of a biological mode of action involving an induced metabolic, immunological or pharmacological action). The device or drug classification, in turn, can have major ramifications as to the cost and length of time that it may take to get a new therapeutic into clinical practice, and available to patients.

It is with this issue in mind that we have, over the last 3 years, developed a real-time in situ molecular tracking system specifically for explorations of the cell death pathways (and therefore modes of action) for controlled in vitro cell cultures in the presence of MFH-inducing magnetic fields. This has involved both the development of the requisite instrumentation, viz. a specially engineered magnetic field appliance incorporated into a fluorescent/optical live-cell imaging microscope, and the development of an imaging protocol capable of delivering substantive information on cell death pathways. Although another group has independently been working on combined MFH/microscope instrumentation [12], we report here, for the first time, on a complete system of both instrumentation and imaging protocol for the purpose of understanding the primary modes of action of magnetic hyperthermia. We take, as a paradigmatic exemplar, the action of $\mathrm{MFH}$ on the DX3 human melanoma cell line.

Melanoma is an aggressive disease that accounts for ca. $4 \%$ of all deaths by cancer, and nearly $80 \%$ of the ones related to skin cancer, with a 5-year survival expectancy of ca. $14 \%$ [13]. The initial post diagnosis treatment is usually surgical removal, but the invasive nature of melanoma often necessitates further treatment to ensure eradication and limit recurrence. Understandably, then, there is a clinical drive towards finding better and improved interventions to treat melanoma, and MFH, either as a stand-alone treatment or in conjunction with anticancer drugs, is one of the methods that is being explored.

Recent preclinical studies on MFH treatment of murine melanoma have shown encouraging results [14-18]. However, the control over the treatment intensity was rather limited, frequently leading to tissue necrosis, with the associated possible side effects that necrosis brings (such as vascular disruption and scarring), as well as the subsequent need for surgical removal of the dead tissue. It would clearly be preferable to move towards less aggressive apoptotic cell death pathways, but to do so it is imperative to distinguish between the two pathways and relate them to the dose-response characteristic of the MFH treatment.

To this end we have built and used a bespoke realtime in situ MFH imaging system to explore the apoptotic and/or necrotic cell death pathways exhibited by DX3 human melanoma cells inoculated with iron oxide nanoparticles in response to the application of time-varying magnetic fields. Prior to heating, the DX3 cells were loaded with citric acid-coated iron oxide nanoparticles to a concentration ranging from ca. 210 to $400 \mathrm{pg}$ of iron oxide per cell, which was found to be sufficient to deliver intracellular hyperthermia in response to a time-varying magnetic field, but not so high as to affect the viability of the cells under normal (zero field) conditions. The nanoparticles were specifically chosen to be ones that exhibited excellent magnetic heating properties, with an intrinsic loss parameter of $4.1 \mathrm{nHm}^{2} \mathrm{~kg}^{-1}$ [19]. To monitor the cell death pathways, two fluorescent markers were used: (i) Annexin V-FITC for early-stage apoptosis, a pseudogreen-colored membrane stain activated by internal-to-external lipid exchange in the cell membrane; and (ii) either DRAQ7 or propidium iodide (PI) for late-stage apoptosis or necrosis, both of which are pseudored-colored nuclear stains that cannot penetrate intact membranes.

Cell death pathway experiments were performed under a selection of different conditions. In one experiment of particular note, when the cells were subjected to MFH at a level of ca. $145 \mathrm{nW}$ per cell for 2 $\mathrm{h}$, clear evidence of delayed-onset apoptosis was seen. In this case, all of the cells in the culture remained viable for $1 \mathrm{~h}$ after the MFH was applied, but then one-by-one the cells started to die, until, after a further $18 \mathrm{~h}$ had elapsed, all the cells were dead. Control experiments were performed to rule out the possibility that this might be a bystander effect, indicating that this is indeed a hitherto unknown effect. It is hoped that MFH-induced delayed-onset apoptosis may be of significant clinical interest, given the likelihood that the idiopathic burden on healthy tissue associated with such a treatment will be much less than that involved with traditional heat-based therapies based on microwave or radiofrequency radiation or ultrasound. 


\section{Materials \& methods}

Microwave-assisted synthesis of citric acid-

coated iron oxide nanoparticles

Unless otherwise stated, all reagents were obtained from Sigma Aldrich, UK, and used as received. The synthesis route was the same as was previously reported in [19] for the sample identified therein as 'CA-ioH'.

Citric acid-coated iron oxide nanoparticles (CAIONPs) were made by co-precipitation of ferric and ferrous chloride salts with sodium carbonate and post precipitation addition of a citric acid solution, with the aid of a SP-Discovery Microwave oven (CEM Corporation, USA). Briefly, a solution of $\mathrm{FeCl}_{2} \cdot 4 \mathrm{H}_{2} \mathrm{O}(0.02 \mathrm{M}$, where $\mathrm{M}$ denotes molarity, i.e., $0.02 \mathrm{M}=0.02 \mathrm{~mol} / \mathrm{l}$ ) and $\mathrm{FeCl}_{3} \cdot 6 \mathrm{H}_{2} \mathrm{O}(0.04 \mathrm{M})$ was transferred into a vial and sealed with a pressure cap. The solution was heated to $60^{\circ} \mathrm{C}$ (microwave power setting $300 \mathrm{~W}$ ) and sodium carbonate aqueous solution $(1 \mathrm{M})$ was added with a syringe pump ( $2 \mathrm{ml} / \mathrm{min}$ ) (World Precision Instruments, UK). The solution was kept at $60^{\circ} \mathrm{C}$ for $10 \mathrm{~min}$

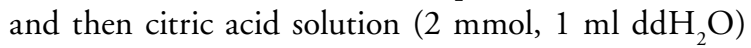
was added. The solution was then maintained at $60^{\circ} \mathrm{C}$ for a further $10 \mathrm{~min}$. The obtained nanoparticles were then washed by magnetic separation and redispersed in $\mathrm{ddH}_{2} \mathrm{O}$.

The magnetic heating properties of the as-made CA-IONPs were determined using standard methods for nonadiabatic test conditions [20], and quantified in terms of the intrinsic loss parameter (ILP) of the particles.

\section{Cell culture \& magnetic nanoparticle loading}

DX3 human melanoma cells were obtained from the Barts Cancer Institute, Queen Mary University of London. Adherent cells were cultured in high glucose Dulbecco's Modified Eagle Medium (DMEM) containing 10\% fetal calf serum (FCS), $1 \%$ penicillin and $1 \%$ stable L-glutamine (complete DMEM) [21]. Cells were incubated at $37^{\circ} \mathrm{C}$ and $8.5 \% \mathrm{CO}_{2}$. The culture medium was changed every other day and the cells passaged every 5 days.

Initially, $2 \times 10^{7}$ cells were cultured prior to starving using FCS-free complete DMEM to induce subsequent uptake of CA-IONPs. After $12 \mathrm{~h}$, the cells were fed with complete DMEM including $0.5 \mathrm{mg} / \mathrm{ml}$ of CA-IONPs and returned to culture for $12 \mathrm{~h}$. Afterwards, the cell flasks were rinsed five-times with prewarmed $\left(37^{\circ} \mathrm{C}\right)$ phosphate buffered saline (PBS) prior to harvesting.

DX3 cells were harvested with Accutase [22,23], washed twice with prewarmed PBS by centrifugation $\left(1100 \mathrm{rpm}, 10 \mathrm{~min}, 4^{\circ} \mathrm{C}\right)$ and fixed $(3.5 \%$ paraformaldehyde and $2 \%$ sucrose in PBS) for $10 \mathrm{~min}$ at room temperature. The obtained cell pellet was washed twice by centrifugation $\left(1100 \mathrm{rpm}, 10 \mathrm{~min}, 4^{\circ} \mathrm{C}\right)$ with $\mathrm{ddH}_{2} \mathrm{O}$. The number concentration of cells in the final cell suspension was counted by flow cytometry (Accuri C6, BD Biosciences).

The internalized nanoparticles were quantified using a superconducting quantum interference device vibrating sample magnetometer (SQUID-VSM, Quantum Design, USA) by recording a room temperature magnetization curve, and comparing the measured saturation magnetization to that obtained from a calibration sample of neat CA-IONPs at a known concentration. The measured concentration of particles was combined with the measured number concentration of cells in the sample to estimate the average mass concentration of CA-IONPs per cell.

\section{Histology \& localization studies}

DX3 human melanoma cells were cultured on glass coverslips in a 24-well plate at $5 \times 10^{4}$ cells/well and cultured for $24 \mathrm{~h}$ prior to loading. Cells were starved, loaded with magnetic particles and fixed, as described above. Cells were stained for iron content with Prussian Blue $\left(1: 14 \% \mathrm{HCl}: 4 \% \mathrm{~K}_{4} \mathrm{Fe}(\mathrm{CN})_{6}, 10 \mathrm{~min}\right.$, twotimes), rinsed with $\mathrm{ddH}_{2} \mathrm{O}$ and counterstained with nuclear fast red ( $2 \mathrm{~min})$. Stained cells were dehydrated with ascending alcohols by immersion in $70 \%$ ethanol (2 min), 100\% ethanol (1 min, two-times) and xylene $(10 \mathrm{~min})$ and mounted. The cells were assessed by light microscopy using an inverted microscope (DMI6000B, Leica, UK).

\section{In vitro MFH treatment on cell suspensions}

DX3 cells were cultured and loaded with particles as described above, then harvested with Accutase and resuspended $\left(1 \times 10^{6}\right.$ cells $\left./ \mathrm{ml}\right)$ in phenol-red-free complete DMEM media containing 25 mM HEPES. They were then loaded into $1.5 \mathrm{ml}$ Eppendorf tubes and placed in a controlled alternating magnetic field supplied by a desktop solenoid-based Magnetic Alternating Current Hyperthermia system (MACH system, Resonant Circuits Ltd, UK). This system comprised a six-turn water-cooled solenoid coil capable of delivering a magnetic field with near-uniform (within $\pm 6 \%$ ) intensity over a cylindrical volume of height ca. $16 \mathrm{~mm}$ and diameter ca. $20 \mathrm{~mm}$ at the center of the solenoid (Supplementary Information S1).

Time varying magnetic fields of amplitude 6.6, 10.5, $12.0,14.7$ and $16.1 \mathrm{kA} / \mathrm{m}$ were applied at a constant frequency of either 911 or $950 \mathrm{kHz}$, for a total treatment period of $2 \mathrm{~h}$ per sample. Aliquots were taken for analysis before, during and immediately after the hyperthermia treatment (i.e., at $t=0,1$ and $2 \mathrm{~h}$ ). After treatment, half of the remaining cells were transferred 
to culture plates and incubated for 2 days, with their viability being assessed at $t=24$ and $48 \mathrm{~h}$. The other half of the cells were kept in their Eppendorf tubes, and their viability assessed at $t=5 \mathrm{~h}$. Control experiments were carried out under each of the hyperthermia experimental conditions (i.e., for each of the six time points and for each of the five field and frequency conditions), using native (not magnetically loaded) DX3 cells.

Wherever possible, both before and during the experiments, the cells were kept at $37^{\circ} \mathrm{C}$ in buffered media to maintain incubation ambient conditions, and in the dark to minimize light impact reducing cell damage from light exposure. During the hyperthermia treatment, the temperature of the cell culture medium was monitored using a Luxtron FOT fluoroptic probe thermometer (LumaSense Technologies, USA). A mounting device was used to ensure that the thermometer tip was placed at the same position in the Eppendorf tubes each time, to allow for direct comparison between the different experiments.

\section{In situ MFH treatment on cell monolayers}

DX3 cells were seeded on a 35-mm Fluorodish cell culture dish (World Precision Instruments, USA) with a working window of $10 \mathrm{~mm}$, at $4 \times 10^{5}$ cells/ well. Cell loading was carried out as previously stated. After incubation, the cell layer was washed two-times with prewarmed $\mathrm{PBS}\left(37^{\circ} \mathrm{C}\right)$. The wells were supplemented with fresh phenol-red-free complete DMEM media containing $25 \mathrm{mM}$ HEPES, and the cells were then stained for live imaging with Annexin V-FITC and DRAQ7 [24] $(1 \mu \mathrm{l} / 100 \mu \mathrm{l}$ media) (BD Biosciences, UK). Cell dishes were kept in darkness before being and transferred to a live-cell-imaging inverted microscope (DM1600B, Leica, UK) equipped with a Pecon BL-TIRF incubation chamber and an Insert P microscope stage heater and cover (Leica, UK) and a bespoke MACH system (Resonant Circuits Ltd, UK). The Insert P microscope stage was modified using replacement plastic parts in place of the metal parts that would otherwise have been subject to nonspecific eddy-current heating from the MACH system.

The bespoke 'pancake' geometry MACH system was specifically designed by Resonant Circuits Ltd for in situ operation in the live-cell-imaging microscope (Supplementary Information S2). It featured a fiveturn drive coil made from 2-mm diameter copper pipe wound into a flat spiral with $0.5-\mathrm{mm}$ spacing between turns, and inner and outer diameters of 15 and $44 \mathrm{~mm}$. The coil was mounted in the microscope, ca. $5 \mathrm{~mm}$ above the tissue culture dish, and aligned so that the cells were viewable through the center of the coil. A bespoke nonmetallic baseplate was made to incorpo- rate both the coil and the culture dish within the $\mathrm{CO}_{2}-$ controlled incubation chamber. The entire microscope, including the pancake-MACH system, was set within a temperature-controlled chamber, which was set to $37^{\circ} \mathrm{C}$ throughout the $\mathrm{MFH}$ treatment, and the subsequent post treatment imaging.

The cells were allowed to equilibrate for $1 \mathrm{~h}$ in the chamber before they were subjected to a time-varying magnetic field of amplitude $10.5 \mathrm{kA} / \mathrm{m}$ and frequency of $950 \mathrm{kHz}$ for $2 \mathrm{~h}$. Cells were kept in the incubation chamber at $8.5 \% \mathrm{CO}_{2}$ and imaged in situ for $24 \mathrm{~h}$. Time-lapse images were captured hourly using three channels: phase contrast, far-red fluorescence (CY5; excitation/emission wavelengths $=647 / 670 \mathrm{~nm})$ and green fluorescence (FITC; 495/ $519 \mathrm{~nm}$ ).

\section{Nanoparticle cytotoxicity \& cell viability}

Nanoparticle cytotoxicity was studied with a 'cell counting kit 8' (NBS Biologicals, UK), used as stated by the manufacturer. DX3 cells were seeded on a 96-well-plate $\left(1 \times 10^{4}\right.$ cells/well $)$ and returned to culture. Cell loading was carried out as previously stated at concentrations ranging from $0-0.5 \mathrm{mg} / \mathrm{ml}$. Cells were rinsed (five-times) with prewarmed $\mathrm{PBS}\left(37^{\circ} \mathrm{C}\right)$ to remove any free iron oxide nanoparticles and supplemented with complete phenol-red-free DMEM medium and the WTS8 solution. Cells were returned to culture for $2 \mathrm{~h}$ and the absorbance measured at $450 \mathrm{~nm}$ (SpectraMax M2e, Molecular Devices, UK). A positive control for cell toxicity was provided with $10 \% \mathrm{NaN}_{3}$.

Cell viability before, during and after the in vitro hyperthermia treatments on cell suspensions was assessed using a FITC-Annexin V Apoptosis Detection Kit (BD Pharmingen, BD Biosciences, UK); propidium iodide solution was included in the same kit. Aliquot cell suspensions (ca. $10^{5}$ cells) were taken at time points $t=0,1,2,5,24$ and $48 \mathrm{~h}$, as described above. Cells were stained before analysis by flow cytometry (Accuri C6 Flow Cytometer, BD Biosciences, UK).

Cell viability before and during the in situ hyperthermia treatment on cell monolayers was assessed using both Annexin V-FITC (green) and DRAQ7 (farred) stains (at $1 \mu \mathrm{l}$ stain per $100 \mu \mathrm{l}$ media) (BD Biosciences, UK). Fluorescence images were captured every hour for $24 \mathrm{~h}$, starting from immediately before the cells received 2-h exposure to the alternating magnetic field. The imaged region, which covered ca. $230 \mu \mathrm{m} \times$ $300 \mu \mathrm{m}$ of the plate, was kept constant throughout to enable longitudinal tracking of individual cells.

\section{Results}

In this study, citric acid-coated iron oxide nanoparticles (CA-IONPs) were used to deliver intracellular 
heating to DX3 human melanoma cells. The particles were synthesized by co-precipitation of ferric and ferrous chloride salts, with sodium carbonate, in a microwave reactor [19]. Subsequently, citric acid was added to the solution to provide a surface coating with good biocompatibility, transport and cellular internalization properties [25-28]. The particular CA-IONPs chosen here were optimized for their magnetic heating properties. Their measured intrinsic loss parameter (ILP $\approx 4.1 \mathrm{nHm}^{2} \mathrm{~kg}^{-1}$ [19]) is comparable to that of the best superparamagnetic heating materials reported to date (Supplementary Information S3).

Transmission electron microscopy (TEM) analysis showed that the CA-IONPs were multicore particles with a mean core diameter of $17 \pm 3 \mathrm{~nm}$ (Figure 1A \& Supplementary Information S4). Dynamic light scattering analysis indicated that the CA-IONPs had a mean hydrodynamic diameter of ca. $66 \mathrm{~nm} \mathrm{-}$ substantially more than the $17 \mathrm{~nm}$ core diameter measured by TEM, and consistent with the particles being multicore in their nature. From these two measurements the mean number of cores per particle was estimated to be $N \approx 35$, assuming a loose random packing of the constituent core particles, with a $60 \% \mathrm{v} / \mathrm{v}$ content [19].

Histology data on the CA-IONP-incubated DX3 cells showed that their morphology was not affected by the presence of the nanoparticles, and cytotoxicity studies showed that even after $12 \mathrm{~h}$ of incubation with $0.5 \mathrm{mg} / \mathrm{ml}$ of CA-IONPs there were no significant effects on cell viability (Student's $t$-test, two-tailed, p > 0.05) (Supplementary Information S5). Following Prussian blue and nuclear fast red staining, optical microscopy of the incubated cells showed ring-like par- ticle agglomerations in some images (Figure 1B), consistent with intracellular uptake of the nanoparticles and their subsequent arrangement in the cytoplasm, and exclusion from the cell nucleus. The highest magnification TEM images (Figure 1C) confirmed this assessment by revealing discrete clusters of nanoparticles at subcellular length scales, as is typical of the presence of internalized nanoparticles in endosomes or similar vesicles.

Cytometer and magnetometer data indicated that when incubated for $12 \mathrm{~h}$ with the $0.5 \mathrm{mg} / \mathrm{ml}$ preparation of CA-IONPs, the DX3 cells took up and retained, on average, ca. $315 \mathrm{pg}$ of iron oxide per cell, with the batch-to-batch variation ranging from $210 \mathrm{pg} / \mathrm{cell}$ up to $400 \mathrm{pg} / \mathrm{cell}$ (Table 1 \& Supplementary Information S6). These are relatively high levels of uptake, e.g. compared with the $60 \mathrm{pg} / \mathrm{cell}$ that was reported previously for the uptake of dextran-coated iron oxide nanoparticles in rabbit mesenchymal stem cells [29], and are indicative of the effectiveness of the citric acid coating in enhancing the internalization capacity of the particles, while still avoiding disruption to the cell's viability.

In vitro MFH experiments on the CA-IONP-loaded cells were performed using a solenoid-based desktop $\mathrm{MACH}$ system, operating at the magnetic field intensities and frequencies listed in Table 1. For each set of experiments at a given field and frequency setting, a fresh batch of cells was prepared. The resultant MFHinduced thermal load in the cells was estimated from the measured concentration of particles per cell, and the known heating capacity of the particles: these gave rise to estimates for the load that ranged from ca. 35 $\mathrm{nW} /$ cell up to ca. $390 \mathrm{nW} /$ cell (Table 1). Control experiments were performed on nonloaded cells at each of

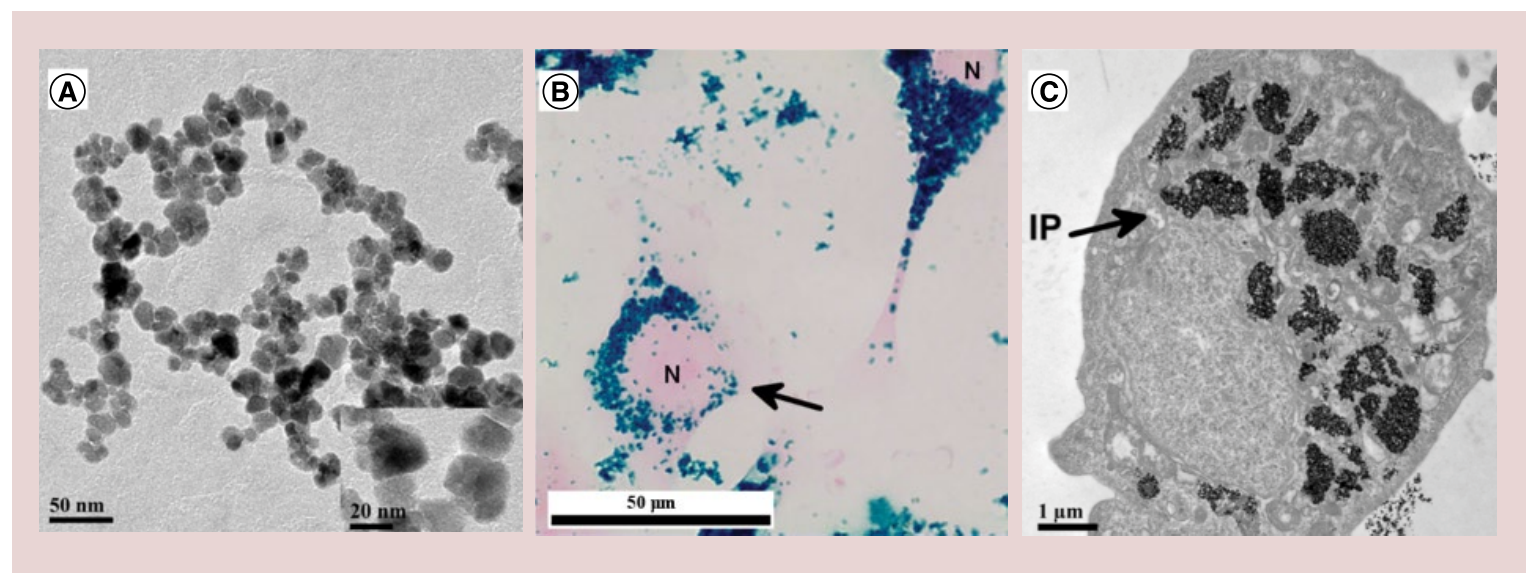

Figure 1. Magnetic nanoparticle internalization in DX3 human melanoma cells. (A) Transmission electron microscopy image of the as-made citric acid-coated iron oxide nanoparticles (CA-IONPs) used in this study. A magnified view is shown in the inset. (B) Bright field image of DX3 human melanoma cells loaded with the CAIONPs stained with Prussian blue and counterstained with nuclear fast red. The ring-like perinuclear iron staining (arrowed) seen around the cell nucleus indicates intracellular uptake. (C) Representative transmission electron microscopy image of a DX3 cell loaded with CA-IONPs.

IP: Internalized nanoparticles in endosomes; N: Nucleus. 


\begin{tabular}{|c|c|c|c|c|}
\hline $\begin{array}{l}\text { Mean loading } m_{\text {cell }} \\
\text { (pg of iron oxide } \\
\text { per cell) }\end{array}$ & Coil current/(A) ${ }^{\dagger}$ & $\begin{array}{l}\text { Field intensity } H \\
(\mathrm{kA} / \mathrm{m})^{\dagger}\end{array}$ & Frequency $f(\mathrm{kHz})^{\ddagger}$ & $\begin{array}{l}\text { Thermal load } P \\
\text { (nW per cell) }\end{array}$ \\
\hline \multicolumn{5}{|c|}{ In vitro experiments on cell suspensions } \\
\hline $210 \pm 10$ & $50.4 \pm 0.7$ & $6.6 \pm 0.1$ & 950 & $35 \pm 5$ \\
\hline $315 \pm 15$ & $80.2 \pm 1.5$ & $10.5 \pm 0.2$ & 950 & $135 \pm 15$ \\
\hline $370 \pm 20$ & $91.6 \pm 1.5$ & $12.0 \pm 0.2$ & 950 & $210 \pm 20$ \\
\hline $285 \pm 15$ & $112.2 \pm 2.2$ & $14.7 \pm 0.3$ & 911 & $230 \pm 20$ \\
\hline $400 \pm 20$ & $122.9 \pm 2.2$ & $16.1 \pm 0.3$ & 911 & $390 \pm 35$ \\
\hline \multicolumn{5}{|c|}{ In situ experiment on cell monolayers } \\
\hline $315 \pm 75^{\S}$ & $80 \pm 4$ & $10.8 \pm 0.5$ & 950 & $145 \pm 45$ \\
\hline \multicolumn{5}{|c|}{$\begin{array}{l}\text { The mean magnetic nanoparticle loading per cell, } m_{\text {cellf }} \text { determined by cytometer and magnetometer measurements; the peak current in the } \\
\text { coil, I; the corresponding peak applied magnetic field intensity, } \mathrm{H} \text { : the frequency of the applied field, } f \text {; the deduced mean thermal load, } P= \\
m_{\text {cell }} \text { ILP H2 } f \text {, where ILP }=4.1 \pm 0.1 \mathrm{nHm}^{2} \mathrm{~kg}^{-1} \text { is the CA-IONP's intrinsic loss parameter. } \\
{ }^{+B O t h} \text { current and field intensity vary sinusoidally with time, with instantaneous values / } \sin (\omega t+\varphi) \text { and } H \sin (\omega t+\varphi) \text {, respectively, where } \\
\omega=2 \pi f \text {, and } \varphi \text { is a constant. } \\
{ }^{*} \text { Negligible error was determined on the generator frequency. } \\
{ }^{5} \text { Direct measurement of the loading was not possible for the in situ experiment, so the figure quoted is an estimate based on the mean and } \\
\text { standard deviation of the loadings recorded in the in vitro experiments. }\end{array}$} \\
\hline
\end{tabular}

the magnetic field intensities and frequencies, allowing direct comparison of the influence of the CA-IONPs on the cellular responses.

During the $2 \mathrm{~h}$ of MFH treatment, the temperature of the cellular suspension medium (which we shall refer to as the 'local environment temperature', $\left.T_{\text {local }}\right)$ was monitored using a fluoroptic probe. In all cases the $T_{\text {local }}$ temperature increased on application of the $\mathrm{MFH}$, and reached a plateau after ca. $20 \mathrm{~min}$ that was sustained until the MFH field was removed (Supplementary Information S7). These measured $T_{\text {local }}$ temperatures are shown in Figure 2A for both the loaded and control cells. The data show nonspecific peripheral heating effects at the two highest magnetic field intensities, where in both cases the $T_{\text {local }}$ temperatures in the controls exceeded $40^{\circ} \mathrm{C}$. Such peripheral heating effects are well documented [20], and are an unavoidable consequence of the heat generated by the currents flowing through the electromagnetic coil at these highest fields. However, it is also notable from Figure 2A that in all cases the $T_{\text {local }}$ temperature recorded for the loaded cells was ca. $5-8^{\circ} \mathrm{C}$ higher than that in the control cells, indicating that the expected magnetic heating effect is indeed present. It is also notable that at the three highest thermal loadings (those exceeding $200 \mathrm{nW} /$ cell) the $T_{\text {local }}$ temperatures exceeded the $42^{\circ} \mathrm{C}$ benchmark that is widely considered to be a threshold for cellular damage due to environmental heating [30].

The local environment heating effect was further explored by performing flow cytometry experiments on the loaded and controls cells (Supplementary Information 58). Two fluorescent markers were used: green Annexin V fluorescein isothiocyanate (FITC) as a marker of early-stage apoptosis, and red propidium iodide (PI) as a marker for later-stage apoptosis and/or necrosis. As shown in Figure 2B \& C the percentage of the original cell population that were still alive at time $t=2 \mathrm{~h}$ (immediately after the MFH treatment) and at $t=48 \mathrm{~h}$ showed similar trends as were seen with $T_{\text {local }}$ At both timepoints the control cells remains almost $100 \%$ viable up to ca. $200 \mathrm{ng} /$ cell thermal load, but showed significant cell death at higher loads. Meanwhile the CA-IONPloaded cells showed progressively increasing levels of cell death across the entire range of thermal loadings.

The morphological and structural integrity of the cells immediately following the MFH treatment was assessed by TEM (see Figure 3). Treatment under thermal loads of 135 and $210 \mathrm{nW} /$ cell did not affect the integrity of the cells (Figure 3A \& B); however, the formation of vacuoles in the cytoplasm at these MFH levels are indicative signs of cellular apoptosis $[31,32]$. The size and number of the vacuoles increased with increasing thermal load, with the additional appearance of cell blebbing, which is a characteristic of more advanced cellular apoptosis [32-34]. Complete loss of cell membrane integrity with extreme damage to the internal structure of the cell was observed at higher thermal loads, as evident in the $390 \mathrm{nW} /$ cell case shown in Figure 3C. Under these conditions, some of the cells were found to have swelled up, and the cytoplasm and all the organelles were disrupted, consistent with the cells having experienced a rapid and possibly violent process of necrosis and cell death at this elevated level of thermal loading. 
The time-dependent nature of the effect on the DX3 cells of the in vitro MFH treatments was analyzed by expanding the previously described flow cytometry measurements to include each individual timepoint and thermal load condition, and by separating out data on each sample population's percentage of live cells, FITC-positive cells and PI-positive cells. These data are summarized in Figure 4, and provided in full in the Supplementary Information 58, for the CA-IONPloaded cells.

It is clear on inspection of Figure 4 that in all cases the effect on the cell populations extends beyond the initial $2 \mathrm{~h}$ of the MFH treatment. At the lowest loading of $35 \mathrm{nW} /$ cell the live cell count was $85 \%$ at $2 \mathrm{~h}$ but fell to $50 \%$ at $48 \mathrm{~h}$, while both the FITC- and PI-positive cells showed similar trends, starting from low levels at $2 \mathrm{~h}(5-15 \%)$ and rising to moderate levels (30-40\%) at $48 \mathrm{~h}$. At moderate loadings, such as the 135 and 210 $\mathrm{nW} /$ cell cases, similar trends were evident, albeit reaching lower live cell counts (25\%), and higher FITC- and PI-positive counts $(60-70 \%)$, at $48 \mathrm{~h}$. At the highest loading of $390 \mathrm{nW} /$ cell the trends are more marked, with almost complete cell death (only 5\% live cells) and almost all the cells (95\%) registering both the FITC and PI markers. Across the series, in most cases (the exception being the $210 \mathrm{nW} /$ cell case), the population changes between the $t=24$ and $48 \mathrm{~h}$ timepoints were relatively small, of order a few percent, implying that the effect of the MFH treatment was primarily active in the first $24 \mathrm{~h}$ post treatment.

At this point, it was apparent: (i) that the in vitro experimental data had established that MFH treatments at thermal loadings of less than $200 \mathrm{nW} /$ cell could be undertaken without risking any environmental heating effects; (ii) that the majority of the time-dependent effects were observable within $24 \mathrm{~h}$ of the start of the MFH treatment; and (iii) that the combined use of an early-stage apoptosis (FITC) biomarker and a later-stage apoptosis and/or necrosis (PI) biomarker had shown some synchronicity in their rate of change, but that it was impossible to distinguish them on the basis of the flow cytometry data only. Therefore, to further explore the cell death pathway, an in situ MFH treatment experiment was performed using a hybrid live-cell imaging plus magnetic heating system, the latter featuring a bespoke 5-turn spiral pancake-coil MACH appliance.

For the in situ experiment it was necessary to seed the CA-IONP-loaded DX3 cells directly onto a cell culture dish, which meant that it was not possible to directly measure their magnetic loading. As such, the loading of the cells was estimated from the average and standard deviation of all the measurements made on previous batches (see Table 1), giving a value of $315 \pm$ $75 \mathrm{pg} / \mathrm{cell}$. The applied magnetic field intensity was then adjusted to bring the anticipated thermal load
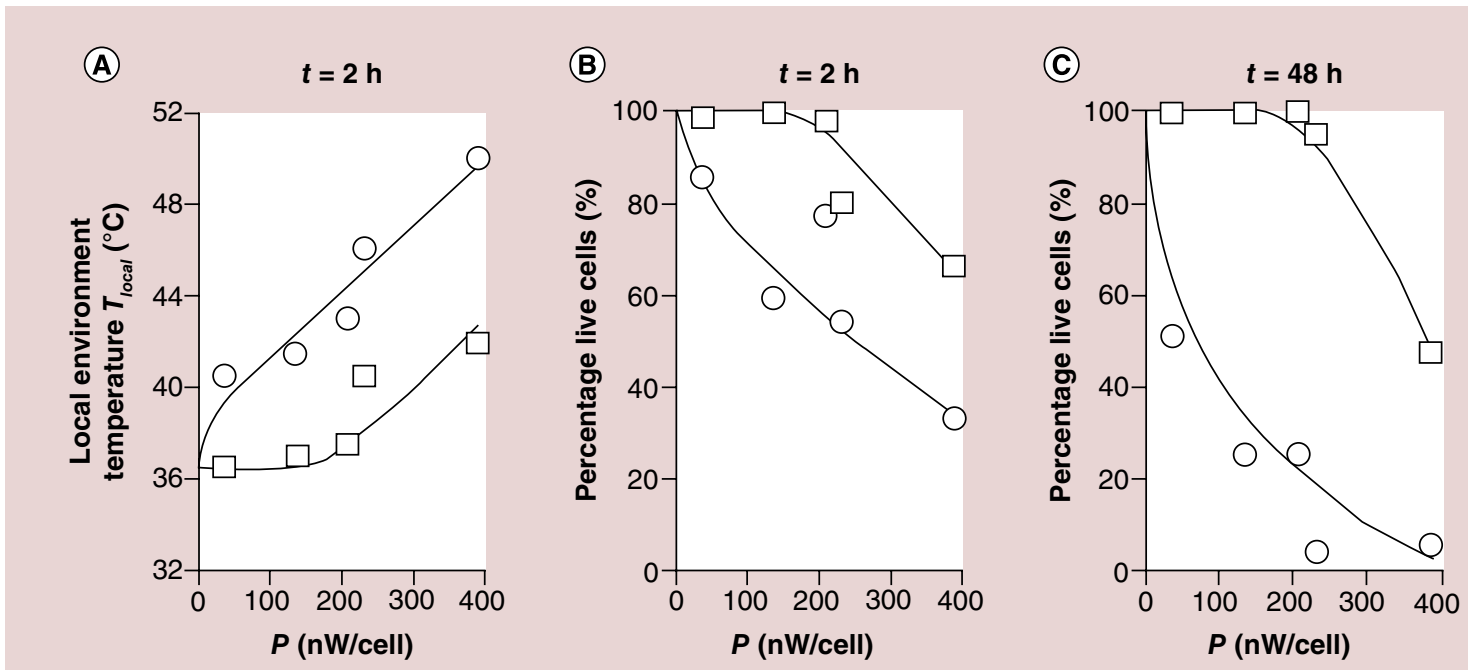

Figure 2. In vitro magnetic field hyperthermia treatment effects in citric acid-coated iron oxide nanoparticleloaded DX3 melanoma cells (circles) and nonloaded controls (squares). (A) The local environment temperature $T_{\text {local }}$ measured in the cell suspension medium during the course of the 2 -h magnetic field hyperthermia treatment (this is the plateau temperature reached at $t \approx 15 \mathrm{~min}$, and sustained until the treatment ceased at $t=2 \mathrm{~h}$ ). (B) The percentage of the original cell population that were alive at time $t=2 \mathrm{~h}$, immediately after the magnetic field hyperthermia treatment. (C) The percentage of the original cell population were alive at time $t=48 \mathrm{~h}$. All data are plotted with respect to the mean thermal load per citric acid-coated iron oxide nanoparticle-loaded cell, $P$, which refers also to the respective field and frequency conditions employed, as listed in Table 1. Solid lines are guides to the eye only. 


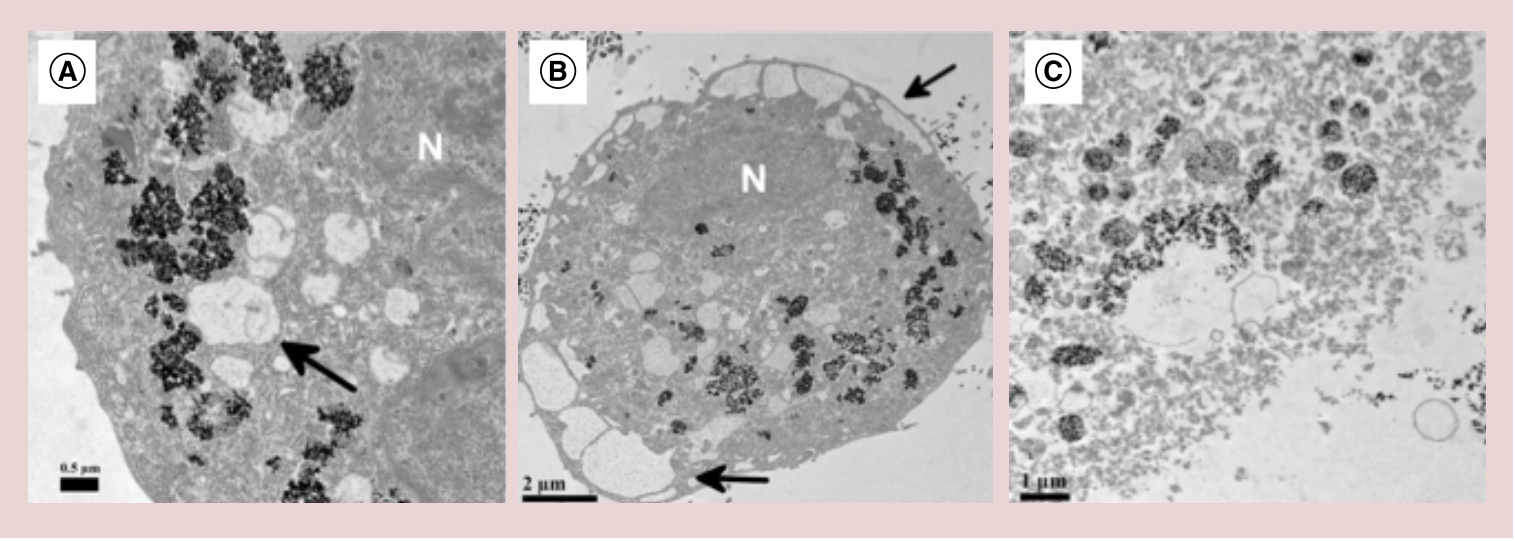

Figure 3. Cell damage after magnetic field hyperthermia treatment under varying field conditions. Representative transmission electron microscopy images of DX3 human melanoma cells after MFH treatment for $2 \mathrm{~h}$ (i.e., recorded at $t=2 \mathrm{~h}$ ) with a magnetic field delivering an average thermal loading of (A) $135 \mathrm{nW} /$ cell;

(B) $210 \mathrm{nW} /$ cell; and (C) $390 \mathrm{nW} /$ cell. The arrows indicate the presence of vacuole formation due to cell apoptosis. $\mathrm{N}$ : Nucleus.

below the $200 \mathrm{nW} /$ cell level above which environmental heating might occur. A field of intensity $10.8 \mathrm{kA} / \mathrm{m}$ at a frequency of $950 \mathrm{kHz}$ was chosen, corresponding to a thermal load of $145 \pm 45 \mathrm{nW} /$ cell.

Cellular responses were observed in real time by fluorescence microscopy using Annexin V-FITC to image early-stage apoptosis and DRAQ7 to image later-stage apoptosis and/or necrosis. DRAQ7 was used in preference to PI as it is designed to be nontoxic, and therefore is better suited to prolonged exposure (in this case $24 \mathrm{~h}$ ) to a given cell culture [24]. The microscope field of view was kept fixed throughout the experiment, which enabled the identification and tracking of all the individual cells that were present in the ca. $230 \mu \mathrm{m}$ $\times 300 \mu \mathrm{m}$ imaged region. For the cases reported here this corresponded to 80 cells in the control experiment, and 65 cells in the active experiment. The data thus obtained are summarized in Figures $5 \& 6$, and in the Supplementary Information 59.

In Figure 5 some representative fluorescence microscopy images from the in situ MFH treatment experiment on CA-IONP-loaded cells are shown. It was notable that no FITC- or DRAQ7-positive cells were observed either during or immediately after the $2 \mathrm{~h}$ of $\mathrm{MFH}$ treatment, and that the first fluorescence appeared at $t=3 \mathrm{~h}$. Thereafter, both FITC (green) and DRAQ7 (red) fluorescence was seen in each individual cell, with, in some cases, the FITC and DRAQ7 appearing at the same time, and, in the majority of the cases, the FITC appearing first, to be followed an hour or more later by the DRAQ7. Some cases of cell contraction and membrane blebbing were seen from $t=4 \mathrm{~h}$ onwards (Figure 5), both of which are characteristic of morphological changes associated with apoptosis [33]. DRAQ7 fluorescence intensity was preserved throughout the experiments, but in some cases the FITC fluorescence faded, being more susceptible to photobleaching.

In Figure 6 the in situ experiment data is presented in a form reminiscent of a survivorship or mortality curve, in this case referring to the cell death pathways of the ensemble of imaged cells. It is clear on inspection of Figure 6 that most CA-IONP-loaded DX3 cells are dead (only 2 of 65 cells remaining alive) by $t=24 \mathrm{~h}$, whereas the majority of the control cells ( 58 of 80 cells) were unaffected by the MFH treatment. From Figure 6 one can also identify the timepoint at which $50 \%$ of the exposed cells had died, viz. at $t_{L D 50}=11 \mathrm{~h}$. In the control experiment, in 2/80 cells DRAQ7 was seen but not FITC, while in 16/80 cells FITC was seen but not DRAQ7. In contrast, in the CA-IONP-loaded cells, none were found to be DRAQ7-positive and FITC-negative, and only 2/65 were FITC-positive and DRAQ7-negative. By far the majority of cells, 61/65, were both FITC-positive and DRAQ7-positive.

For the CA-IONP-loaded cells that exhibited both fluorescent signals during the course of the experiment, the observed time delay $\left(t_{2}-t_{1}\right)$ between the appearance of the FITC (at $t_{1}$ ) and the later appearance of the DRAQ7 (at $t_{2}$ ) was found to follow a reasonably smooth distribution, as shown in Figure 7. It is apparent from these data that in the majority of cases $(50 / 65)$ the late-apoptotic and/or necrotic DRAQ7 biomarker was seen within $3 \mathrm{~h}$ of the appearance of the earlyapoptotic FITC biomarker. Equally, it is clear that in some cells the transition from early to late-stage apoptosis and/or necrosis takes longer, with one showing a $t_{2}-t_{1}$ delay of $9 \mathrm{~h}$.

Although we do not at present have a theoretical model for the progression of MFH-initiated cell death in the DX3 cells, it is notable that the histogram in Figure 7 is reminiscent of a log-normal distribution. 
For this reason we attempted a phenomenological fit to the data by treating the histogram as a point-by-point dataset at times $t_{2}-t_{1}=0.5,1.5, \ldots 9.5 \mathrm{~h}$. The resultant fit is shown as the dashed line in Figure 7. The mean, standard deviation and mode values of this fit were of order $1.1,1.0$ and $1.2 \mathrm{~h}$, respectively.

\section{Discussion}

The citric acid-coated iron oxide nanoparticles (CAIONPs) employed in this study were specifically chosen because of their high intrinsic loss parameter (ILP $\left.\approx 4.1 \mathrm{nHm}^{2} \mathrm{~kg}^{-1}\right)$ and their high level of uptake (210-
$400 \mathrm{pg} / \mathrm{cell}$ ) in our chosen DX3 human melanoma cell line. Taken together, these factors allowed us to explore a very broad range of intracellular thermal loads, from zero up to $P \approx 390 \mathrm{nW} /$ cell. Furthermore, by characterizing the thermal load per cell in this way-something that to our knowledge has not yet become standard practice - we were able to explore in detail the cellular responses in the system in a manner that lends itself to discussion of the dose-response characteristics of magnetic field hyperthermia.

Initial cell viability tests showed that despite the high levels of uptake, that CA-IONP-loaded DX3

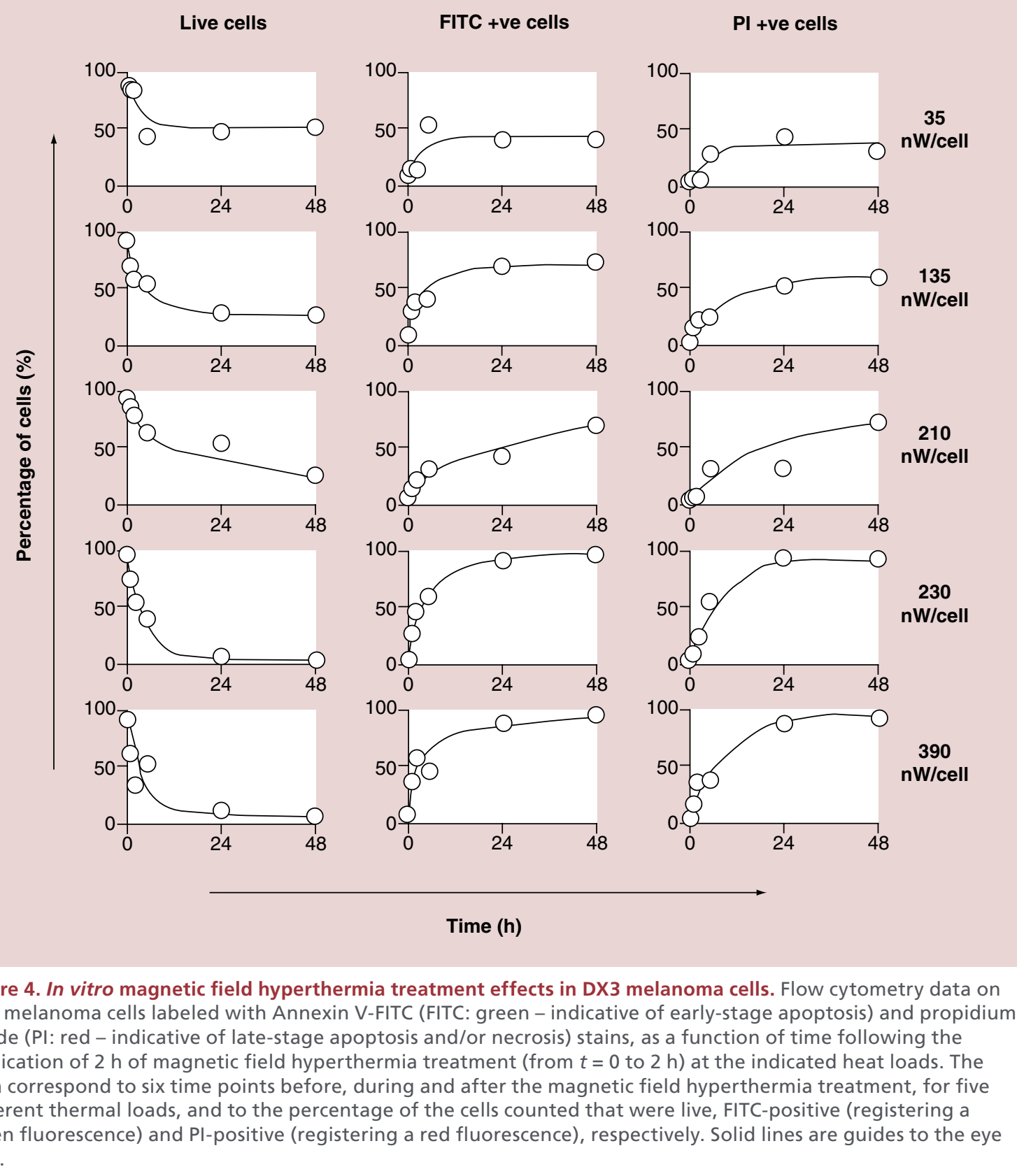




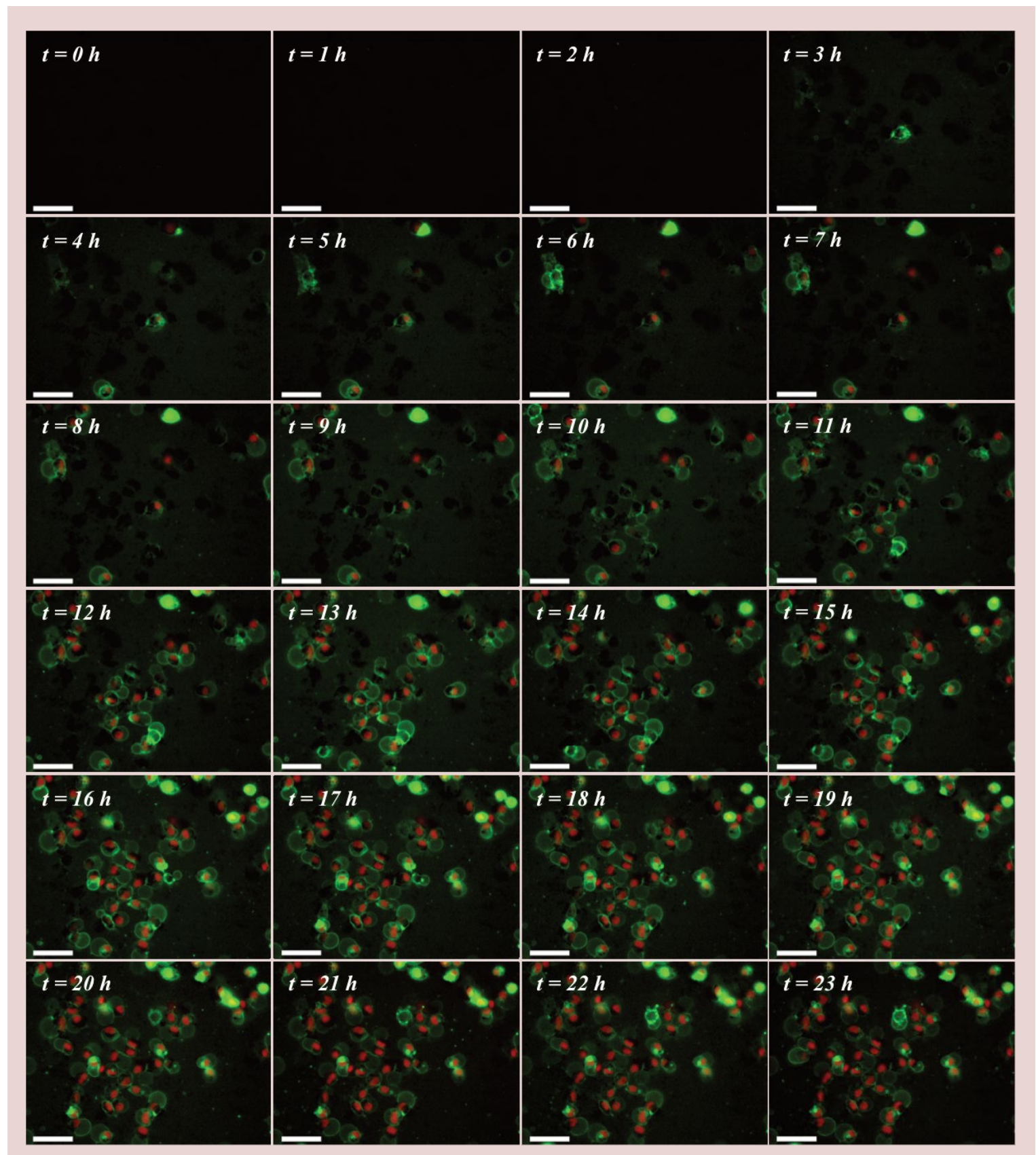

Figure 5. Cell-by-cell real-time tracking of cell death pathways - fluorescence imaging. Fluorescence microscopy images of citric acid-coated iron oxide nanoparticle-loaded DX3 cells during and after $2 \mathrm{~h}$ of magnetic field hyperthermia treatment (from $t=0$ to $2 \mathrm{~h}$ ) with a magnetic field delivering ca. $145 \mathrm{nW} / \mathrm{cell}$ of thermal energy. Cells were labeled with Annexin V-FITC (green) and DRAQ7 (far-red), and images were recorded hourly. Scale bar is $50 \mu \mathrm{m}$ in all images.

cells remained viable, and that the nanoparticles were internalized into endosomes within the cells. Subsequent in vitro $\mathrm{MFH}$ experiments on both nonloaded and loaded cells in suspension, using a solenoid-based $\mathrm{MACH}$ system, showed three distinct phenomena. The first was a nonspecific peripheral heating of the suspension medium due to the large currents flowing in the electromagnetic coils. This led to an environmental heating effect that was apparent in the nonloaded control-cell suspensions at the two highest magnetic field intensities used (viz. at $H=14.7$ and $16.1 \mathrm{kA} / \mathrm{m}$, corresponding to peak currents $I=112$ and $123 \mathrm{~A}$, respectively). Under these conditions, after $2 \mathrm{~h}$ of exposure to the environmental heating, the control cells exhibited significant rates of cell death (of order 20 and 35\%, respectively). That said, under less extreme conditions 
(viz. up to $H=12.0 \mathrm{kA} / \mathrm{m}, I=92 \mathrm{~A}$ ), no significant cell death at all was measured in the nonloaded cells.

The second effect observed in the in vitro experiments was an MFH-specific direct heating due to the presence of the magnetic nanoparticles. This was apparent in the measured local-environment (cell-suspension) temperature, $T_{\text {local }}$, which in all cases was ca. $5-8^{\circ} \mathrm{C}$ higher than in the control suspensions, as well as in the observed quasilinear correlation between $T_{\text {local }}$ and $P$. These are intriguing observations, as they imply that the magnetic heating of the iron oxide nanoparticles is not being confined within endosomes, or even within cells, but rather that some degree of thermal equilibration is taking place throughout the suspension as a whole.

The third phenomenon seen in the in vitro data was that of delayed-onset cell death in the magnetically heated cells. This was evidenced by flow cytometry in combination with dual-marker fluorescent staining; the latter to identify both early-stage apoptosis (Annexin V-FITC: activated by internal-to-external lipid exchange in the cell membrane) and late-stage apoptosis or necrosis (propidium iodide: a nuclear stain that cannot penetrate intact membranes). Definite time-delayed response curves were seen in the data for the proportion of cells that remained alive, as well as for the proportion of cells that were either FTICpositive, or PI-positive, or both. At the two lowest thermal loads ( $\mathrm{p}=35$ and $135 \mathrm{nW} /$ cell) the proportion of FITC-positive cells appeared to be measurably higher than the proportion of PI-positive cells across the 48-h monitoring period, but at higher thermal loads such differences were not so apparent. The implication is that at the lower thermal loads, the progression of cell death via early apoptosis (and internal-to-external lipid exchange in the cell membrane) through to late-

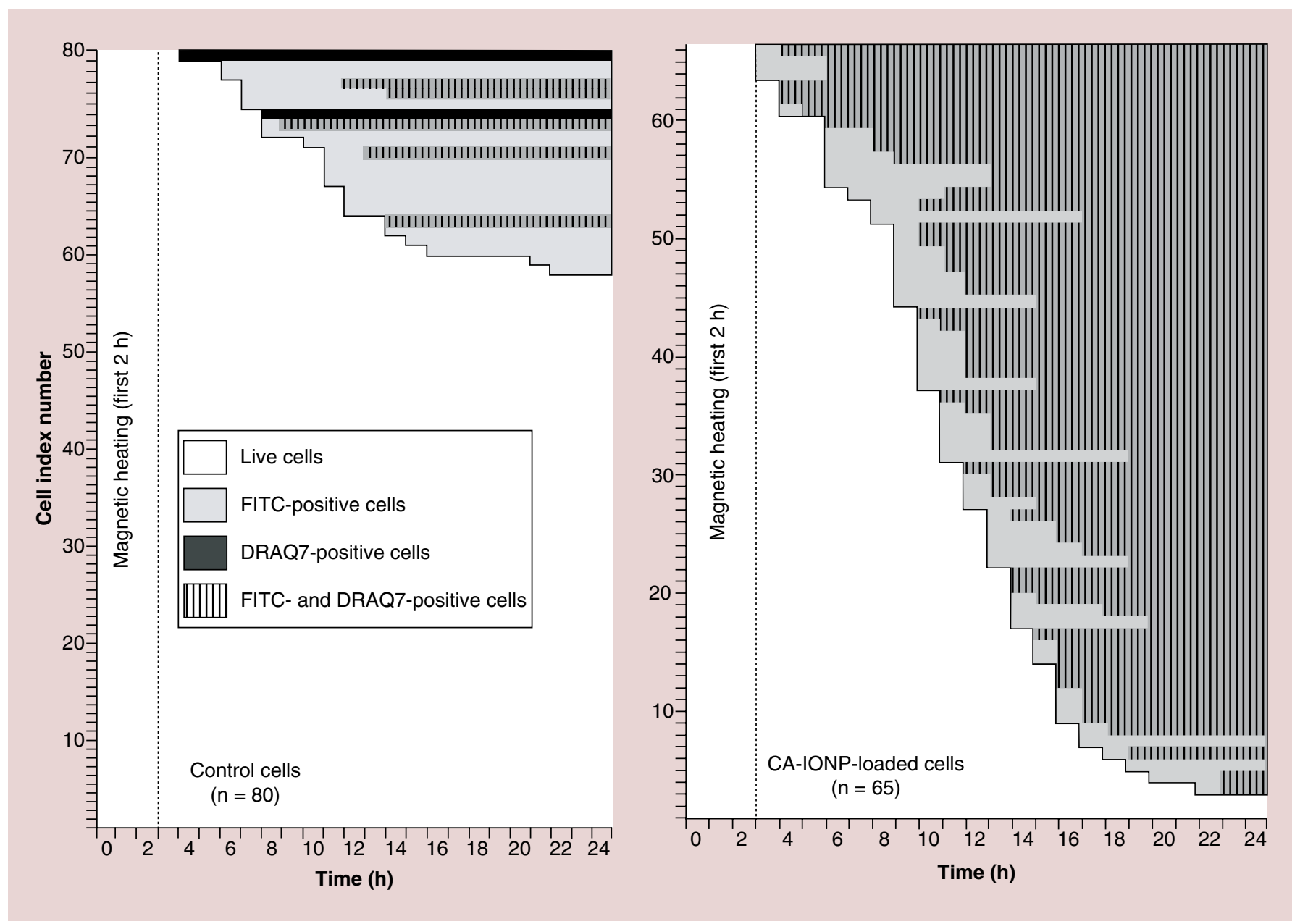

Figure 6. Cell-by-cell real-time tracking of cell death pathways - accumulated mortality curves. Representative mortality curves for control (nonloaded) and CA-IONP-loaded DX3 melanoma cells during and after $2 \mathrm{~h}$ of magnetic field hyperthermia treatment (from $t=0$ to $2 \mathrm{~h}$ ) with a magnetic field delivering ca. $145 \mathrm{nW} /$ cell of thermal energy. Data acquired by tracking individual cells in an in situ magnetic field hyperthermia treatment system. Cells were labeled with Annexin V-FITC and DRAQ7 stains, indicative of early-stage apoptosis and of late-stage apoptosis and/or necrosis, respectively.

CA-IONP: Citric acid-coated iron oxide nanoparticle. 


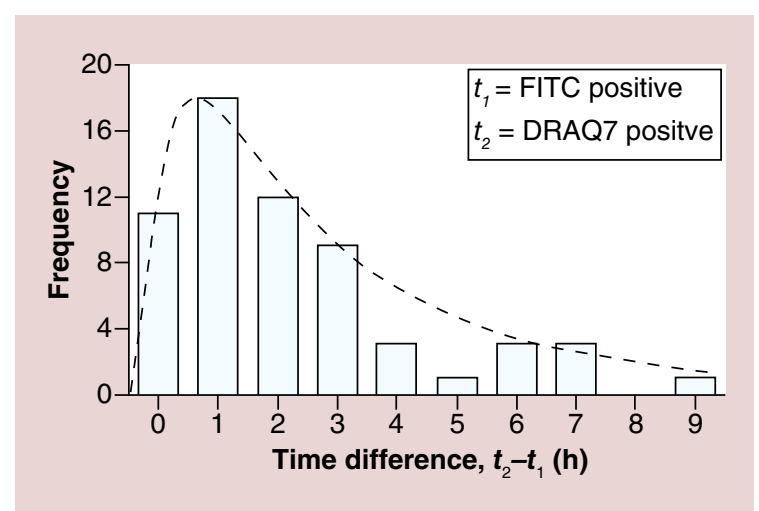

Figure 7. Prolonged cell death instigated by magnetic field hyperthermia treatment of citric acid-coated iron oxide nanoparticle-loaded DX3 melanoma cells. Histogram of the delay between the time of appearance of Annexin V-FITC and DRAQ7 fluorescence biomarkers in citric acid-coated iron oxide nanoparticle-loaded DX3 melanoma cells, after those cells had been subjected to $2 \mathrm{~h}$ of magnetic field hyperthermia treatment delivering ca. $145 \mathrm{nW} /$ cell of thermal energy. Data acquired by tracking individual cells in an in situ magnetic field hyperthermia treatment system. The dashed line is a phenomenological log-normal distribution fit to the data.

stage apoptosis and/or necrosis (that leaves the nucleus exposed as a result of membrane rupture) is sufficiently prolonged that it is measureable; while at the higher thermal loads the progression is faster, and the events cannot be separated. That said, it should be noted that although the in vitro data gives clear evidence for delayed-onset cell death, the evidence as to the cell death pathway is not so well determined, and is largely based on supposition.

For this reason, the in situ MFH experiments on DX3 cell monolayers were especially significant, in that they allowed the time-dependent cell death pathways of individual cells to be monitored and recorded. This cell-by-cell monitoring, and the accumulated mortality curves that were derived from observing 80 control cells and 65 magnetically loaded cells, provided definitive evidence that the sequence of cell death was indeed as had been surmised previously, with membrane lipid exchange preceding the exposure of the cell nucleus by a matter of some hours.

However, before discussing the implications of these results, we should consider the differences observed between the in vitro and in situ experiments, and their origins. The DX3 human melanoma cell line we used is an adherent cell line that grows best under plated conditions with controlled nutrients and $\mathrm{CO}_{2}$ levels. As such, when the DX3 cells are removed from their culture plates and placed as a cell suspension in an Eppendorf tube for the in vitro experiments, they are likely to be in a stressed state, and therefore more susceptible to induced cell death following MFH treatment. In this context it is therefore rather unexpected to note that in the in situ experiment, where the cells were in their adherent state, and where they were subjected to a relatively low thermal load of $145 \mathrm{nW} /$ cell, the level of DRAQ7-indicated cell death in both the control and loaded cells (7/80 and 61/65 after $24 \mathrm{~h}$ ) was significantly higher than in the corresponding in vitro experiments.

One possible explanation for this is that there may have been nonspecific environmental heating in the culture plate medium caused by the proximity of the pancake-coil MACH system, which was operating at a peak current of $80 \mathrm{~A}$. We consider this to be unlikely however, as the proximity of the cells to the coils in the two systems (ca. $5 \mathrm{~mm}$ to the pancake coil, ca. $8 \mathrm{~mm}$ to the solenoid, at closest approach) was similar, and no nonspecific heating had been seen in the in vitro experiment at comparable currents. Also, the live-cell imaging microscope was placed in a thermally regulated $37^{\circ} \mathrm{C}$ chamber, which should have mitigated any such effects.

Another possibility is related to the continuous exposure to the Annexin V-FITC and DRAQ7 fluorescent imaging dyes that the cell cultures were subjected to in situ, as compared with the just-prior-to-measurement addition of the dyes in vitro. It is well known that excited fluorophores generate radical oxygen species (ROS), which can react with cell components such as proteins or nucleic acids, leading to delayed-onset phototoxicity [35,36]. This effect would be present in situ, but not in vitro (where the record of any fluorophore activation was imaged at the same time as any corresponding ROS production). We saw some evidence that such effects were important when we used the automatic focusing feature and ' $z$-stacking' on the in situ imaging camera to find the best focal plane at each timepoint, and observed substantial cell death. Subsequently, when we undertook bright-field manual focusing under lowlevel illumination at each timepoint, and used a narrowband filter to limit the radiation exposure of the cells, we observed significantly reduced mortality rates in both the control and loaded cells. That said, ROS-mediated phototoxicity relies on the fluorophores being activated, which requires that there be dead or dying cells in the culture to begin with. In the control experiments, this was not expected to be the case.

A third explanation is that our expectation that the in situ adherent cells should be in a less stressed, and therefore more resilient state compared with the in vitro nonadherent cells is not correct. This is certainly possible, as the cellular metabolism may well be different between the two environments. It is also 
possible that the effect of the MFH treatment on the DX3 cells may be different for a cell monolayer compared with a cell suspension, as in the latter case there might be more opportunities for the cells to dissipate heat by, for example, transforming the heat energy into mechanical energy via increased Brownian motion.

Consequently, in our estimation the observed differences in cell viability in situ versus in vitro are most likely to be due to intrinsic differences in the cell metabolism and/or MFH response characteristics in the experiments, possibly coupled to delayedonset ROS-mediated phototoxicity effects that would only be observable in situ. Despite this, we believe it is still valid and reliable to compare the results of the two experiments to understand better the effect of the MFH treatment on the cell death pathway.

Thus, returning to the in situ data, it is clear that the MFH treatment had a substantial effect, as evidenced by the near-total cell mortality it elicited, and also that it was definitively a delayed-onset effect, with a smooth progression of cell death proceeding over the 24-h period of the experiment. Furthermore, in all cases the Annexin V-FITC dye was activated at a given cell's membrane at the same time as, or before, the DRAQ7 dye was activated at the same cell's nucleus. These are significant observations indicating that controlled apoptosis-based rather than necrotic cell-death pathways may be achievable in vivo.

Another key observation relates to the evolution of the cell-by-cell responses observed in the in situ data, where the fluorescently activated cells appear one by one at randomly distributed sites on the plate. It is striking that there is no evidence here for any cooperative or intercellular effects. Indeed, given an expectation that there would be environmental (extracellular) heating effects associated with the MFH treatment, one would have expected to see the fluorescence progressively spreading out from a given cell to its neighbors and beyond, in a sequential manner. Instead, it very much appears to be a stochastic, individual cell effect. This leads to the consideration that these are cell-specific events, directly relating to the presence in a given cell of internalized magnetic nanoparticles, and the associated generation, under MFH treatment, of internalized heat.

This is very important for potential in vivo applications, where research teams around the world have been exploring strategies for surface-functionalising magnetic nanoparticles with targeting moieties such as antibodies, antibody fragments, proteins and peptides, with the objective of achieving indication-specific uptake in certain cells (e.g., cancer cells) only, while precluding uptake into healthy cells. This strategy has distinct benefits regarding the ease of administration (e.g., intersti- tial or intravenous injection) and the potential limiting of side effects, but previously there had been little real evidence to support the proposition that MFH treatment could be effective at the level of an individual cell. Indeed, theoretical work has been presented that has precluded the possibility of this being a viable strategy, on the basis that the heat generated in a single cell would not be enough to generate even a localized environmental heating of sufficient magnitude to bring about cell death [37]. It is therefore highly significant to have been able to gather direct evidence for intracellular effects resulting from the internalized generation of heat.

\section{Conclusion}

A series of controlled in vitro and in situ magnetic field hyperthermia treatment experiments have been performed on DX3 human melanoma cell suspensions and monolayers. The effect of intracellular heating achieved by loading the cells with nontoxic concentrations of citric acid-coated iron oxide nanoparticles and subjecting them to a time-varying external magnetic field - has been studied with respect to the cell death pathways that might result from the treatment.

Conclusive evidence has been gathered that indicates: (i) that delayed-onset cell death may be achieved, with data showing that after a 2-h MFH treatment, mortality events were still taking place up to 24 and $48 \mathrm{~h}$ later; (ii) that the extent and timecourse of the cell death over a population of cells can be proportionately controlled by varying the level of the administered thermal load, with higher loads eliciting faster and more complete cell mortalities; (iii) that at moderate thermal loads, cell death proceeded in an orderly fashion, with membranal internal-toexternal lipid exchange preceding rupture and death by a few hours, with the timeline varying from cell to cell; and (iv) that the cell death was due to intracellular heating and did not depend on any heating effects in the local environment. Together these observations provide a body of evidence in support of the proposition that intracellular heating may be a viable means of achieving a controllable, nonaggressive, in vivo treatment modality for human pathological conditions such as cancer.

Looking ahead, it is clear that a great deal more work needs to be done to explore in detail the cellular nature of magnetic hyperthermia. To this end, and in the interest of encouraging the sharing of tangible data that will allow cross-comparisons to be made between different experimental systems and designs, we recommend to our fellow researchers the adoption of three metrics that we have found to be useful here. These are: (i) the mean magnetic nanoparticle loading per cell $\left(m_{\text {cell }}\right.$ in $\left.\mathrm{pg} / \mathrm{cell}\right)$ and the corresponding mean thermal load per cell $(P$, 
in $\mathrm{nW} /$ cell); (ii) the cell-by-cell accumulated mortality curve as obtained from in situ experiments, with the associated timepoint at which $50 \%$ of the exposed cells had died ( $t_{L D 50}$, in hours); and (iii) the cell death pathway histogram of time delay between early apoptosis and late-stage apoptosis or necrosis, as obtained from in situ experiments with appropriate fluorescent biomarkers. It is hoped that by adopting a standard practice around making measurements such as these, a definitive assessment protocol may be developed that could amount to a dose-response characteristic for future magnetic field hyperthermia treatments.

\section{Supplementary data}

To view the supplementary data that accompany this paper, please visit the journal website at: www.futuremedicine.com/ doi/full/10.2217/NNM.15.185

Financial \& competing interests disclosure

The authors thank Dr John Marshall of the Barts Cancer Institute, Queen Mary University of London, for providing the DX3 cell line and for his useful discussions and help with cell culture. C Blanco-Andujar thanks University College London and
The Royal Institution of Great Britain for her PhD studentship. D Ortega is grateful for the support received through the AMAROUT-II Marie Curie Action under the European Commission's FP7 PEOPLE-COFUND program, the grant MAT201347395-C4-3-R from the Spanish Ministry of Economy and Competitiveness, and a Research Fund grant from the UK's Royal Society of Chemistry. NTK Thanh thanks the UK's Royal Society for her University Research Fellowship. Although one of the authors (P Southern) fulfills a part-time paid executive role as Chief Executive Officer for Resonant Circuits Ltd, and another (QA Pankhurst) fulfills a part-time paid advisory role as a Consultant for the same company, their roles in this work have been purely academic. The authors have no other relevant affiliations or financial involvement with any organization or entity with a financial interest in or financial conflict with the subject matter or materials discussed in the manuscript apart from those disclosed.

No writing assistance was utilized in the production of this manuscript.

Ethical conduct of research

The authors state that they have obtained appropriate institutional review board approval or have followed the principles

\section{Executive summary}

\section{Objective}

- To study the real-time cell death pathways in a model system both during and after its exposure to a timevarying magnetic field, and thereby draw conclusions regarding the dose-response characteristics and the primary mode of action of the treatment.

\section{Methods}

- Citric acid-coated iron oxides nanoparticles (core diameter $17 \mathrm{~nm}$ ) were synthesised and loaded into human DX3 melanoma cells at concentrations of $210-400$ pg per cell.

- In vitro and in situ experiments were performed on cell suspensions and monolayers, respectively, wherein the cells received $2 \mathrm{~h}$ of magnetic hyperthermia treatment, delivering a thermal load per cell that ranged from 35-390 nW/cell.

- Real-time monitoring (before, during and up to $48 \mathrm{~h}$ after the treatment) of the cell death pathways was undertaken via flow cytometry (for the suspensions) and fluorescence microscopy (for the monolayers), using fluorophores to report on early-stage apoptosis and on late-stage apoptosis and/or necrosis.

Results

- Magnetic hyperthermia caused delayed onset cell death, the rate and extent of which was proportional to the thermal load. Under certain conditions, mortality events were found to be still taking place even at $48 \mathrm{~h}$ after the treatment.

- At moderate loads (145 nW/cell), membranal internal-to-external lipid exchange preceded rupture and death by a few hours, with the timeline varying from cell to cell. At these loads, no heating effects were measured in the local environments of the cells.

- Analysis of the in situ fluorescence microscopy data provided an accumulated, cell-by-cell mortality curve, from which an estimate of the timepoint at which $50 \%$ of the exposed cells had died was obtained $\left(t_{\text {LDSO }} \approx 11 \mathrm{~h}\right.$, for a thermal load of $145 \mathrm{nW} /$ cell $)$.

\section{Conclusion}

- It is important to consider the delayed-onset cell death pathways that are instigated by magnetic hyperthermia, and recognize that effects may not be fully evaluable until many hours after the treatment itself ends.

- Nonaggressive, targeted cell death is achievable via intracellular heating, with the advantage that a measurable dose-response characteristic may be determined, and a primary mode of action ascertained. As such, magnetic hyperthermia has a real prospect of being usable in future in vivo human treatments. 
outlined in the Declaration of Helsinki for all human or animal experimental investigations. In addition, for investigations involving human subjects, informed consent has been obtained from the participants involved.

\section{References}

Papers of special note have been highlighted as:

- of interest; $\bullet$ of considerable interest

1 Ortega D, Pankhurst QA. Magnetic hyperthermia. In: Nanoscience: Volume 1: Nanostructures through Chemistry. O'Brien P (Ed.). RSC Publishing, London, UK, 60-88 (2012).

- Comprehensive review of the underlying physics of magnetic field hyperthermia (MFH), on the current state of translational research in the field, and on clinical trials to date.

2 Hilger I. In vivo applications of magnetic nanoparticle hyperthermia. Int J. Hyperthermia 29(8), 828-834 (2013).

3 Andreu I, Natividad E. Accuracy of available methods for quantifying the heat power generation of nanoparticles for magnetic hyperthermia. Int. J. Hyperthermia 29(8), 739-751 (2013).

- Survey of calorimetric and magnetic methods for measuring heat dissipation in magnetic nanoparticles, including the available physical models.

4 Dutz S, Hergt R. Magnetic nanoparticle heating and heat transfer on a microscale: basic principles, realities and physical limitations of hyperthermia for tumor therapy. Int J. Hyperthermia 29(8), 790-800 (2013).

5 Fantechi E, Innocenti $\mathrm{C}$, Zanardelli $\mathrm{M}$ et al. A smart platform for hyperthermia application in cancer treatment: Cobalt-doped ferrite nanoparticles mineralized in human ferritin cages. ACS Nano 8(5), 4705-4719 (2014).

6 Asín L, Ibarra MR, Tres A, Goya GF. Controlled cell death by magnetic hyperthermia: effects of exposure time, field amplitude, and nanoparticle concentration. Pharm. Res. 29(5), 1319-1327 (2012).

- $\quad$ Report of controlled cell death by magnetic hyperthermia, which includes early indications of delayed-onset effects.

7 Creixell M, Bohorquez AC, Torres-Lugo M, Rinaldi C. EGFR-targeted magnetic nanoparticle heaters kill cancer cells without a perceptible temperature rise. ACS Nano 5(9), 7124-7129 (2011).

-• The effect of MFH on cell viability and clonogenic survival in a system for which there is no perceptible temperature rise in the environment.

8 Kolosnjaj-Tabi J, Di Corato R, Lartigue L et al. Heat-generating iron oxide nanocubes: subtle "destructurators" of the tumoral microenvironment. ACS Nano 8(5), 4268-4283 (2014).

9 Guardia P, Di Corato R, Lartigue L et al. Water-soluble iron oxide nanocubes with high values of specific absorption rate for cancer cell hyperthermia treatment. ACS Nano 6(4), 3080-3091 (2012).

10 Huang JY, Chen MH, Kuo WT, Sun YJ, Lin FH. The characterization and evaluation of cisplatin-loaded
Open access

This work is licensed under the Creative Commons Attribution 4.0 License. To view a copy of this license, visit http://creativecommons.org/licenses/by/4.0/

magnetite-hydroxyapatite nanop articles (mHAp/CDDP) as dual treatment of hyperthermia and chemotherapy for lung cancer therapy. Ceram. Int. 41(2), 2399-2410 (2015).

11 Haghniaz R, Umrani RD, Paknikar KM. Temperaturedependent and time-dependent effects of hyperthermia mediated by dextran-coated $\mathrm{La} 0.7 \mathrm{Sr} 0.3 \mathrm{MnO} 3$ : in vitro studies. Int. J. Nanomedicine 10, 1609-1623 (2015).

12 Connord V, Clerc P, Hallali N et al. Real-time analysis of magnetic hyperthermia experiments on living cells under a confocal microscope. Small 11(20), 2437-2445 (2015).

- Real-time imaging of MFH using a confocal microscope, focused on immediate effects leading to lysosome membrane permeabilization and assembly.

13 Lens MB, Dawes M. Global perspectives of contemporary epidemiological trends of cutaneous malignant melanoma. Br. J. Dermatology 150(2), 179-185 (2004).

14 Balivada S, Rachakatla R, Wang H et al. A/C magnetic hyperthermia of melanoma mediated by iron $(0) /$ iron oxide core/shell magnetic nanoparticles: a mouse study. BMC Cancer 10, 119 (2010).

15 Rachakatla RS, Balivada S, Seo G-M et al. Attenuation of mouse melanoma by A/C magnetic field after delivery of bi-magnetic nanoparticles by neural progenitor cells. ACS Nano 4(12), 7093-7104 (2010).

- Tumor regression via single and multiple MFH treatments in mice after intravenous delivery of neural progenitor cells loaded with magnetic particles.

16 Sato M, Yamashita T, Ohkura M et al. N-propionylcysteaminylphenol-magnetite conjugate (NPrCAP/M) is a nanoparticle for the targeted growth suppression of melanoma cells. J. Invest. Dermatol. 129(9), 2233-2241 (2009).

17 Ito A, Fujioka M, Yoshida T et al. 4-S-cysteaminylphenolloaded magnetite cationic liposomes for combination therapy of hyperthermia with chemotherapy against malignant melanoma. Cancer Sci. 98(3), 424-430 (2007).

18 Portela A, Vasconcelos M, Fernandes M et al. Highly focalised thermotherapy using a ferrimagnetic cement in the treatment of a melanoma mouse model by low temperature hyperthermia. Int. J. Hyperthermia 29 (2), 121-132 (2013).

19 Blanco-Andujar C, Ortega D, Southern P, Pankhurst QA, Thanh NTK. High performance multi-core iron oxide nanoparticles for magnetic hyperthermia: microwave synthesis, and the role of core-to-core interactions. Nanoscale 7(5), 1768-1775 (2015).

20 Wildeboer RR, Southern P, Pankhurst QA. On the reliable measurement of specific absorption rates and intrinsic loss parameters in magnetic hyperthermia materials. J. Phys. D Appl. Phys. 47(49), 495003 (2014).

- Systematic review of measurement methods for both SAR and ILP, leading to practical recommendations for measurements in nonadiabatic systems. 
21 Marshall JF, Nesbitt SA, Helfrich MH, Horton MA, Polakova $\mathrm{K}$, Hart IR. Integrin expression in human melanoma cell lines: heterogeneity of vitronectin receptor composition and function. Int. J. Cancer 49(6), 924-931 (1991).

22 Vanengeland M, Ramaekers FCS, Schutte B, Reutelingsperger CPM. A novel assay to measure loss of plasma membrane asymmetry during apoptosis of adherent cells in culture. Cytometry 24(2), 131-139 (1996).

23 Bajpai R, Lesperance J, Kim M, Terskikh AV. Efficient propagation of single cells Accutase-dissociated human embryonic stem cells. Mol. Reprod. Dev. 75(5), 818-827 (2008).

24 Akagi J, Kordon M, Zhao $\mathrm{H}$ et al. Real-time cell viability assays using a new anthracycline derivative DRAQ7. Cytometry A 83 (2), 227-234 (2013).

25 Jedlovszky-Hajdú A, Bombelli FB, Monopoli MP, Tombácz E, Dawson KA. Surface coatings shape the protein corona of SPIONs with relevance to their application in vivo. Langmuir 28(42), 14983-14991 (2012).

26 Srivastava S, Awasthi R, Gajbhiye NS et al. Innovative synthesis of citrate-coated superparamagnetic $\mathrm{Fe}_{3} \mathrm{O}_{4}$ nanoparticles and its preliminary applications. J. Colloid Interface Sci. 359(1), 104-111 (2011).

27 Hodenius MaJ, Niendorf T, Krombach GA et al. Synthesis, physicochemical characterization and MR relaxometry of aqueous ferrofluids. J. Nanosci. Nanotechnol. 8(5), 2399-2409 (2008).

28 Behdadfar B, Kermanpur A, Sadeghi-Aliabadi H, Morales MD, Mozaffari M. Synthesis of high intrinsic loss power aqueous ferrofluids of iron oxide nanoparticles by citric acid-assisted hydrothermal-reduction route. J. Solid State Chem. 187, 20-26 (2012).

29 Riegler J, Liew A, Hynes SO et al. Superparamagnetic iron oxide nanoparticle targeting of MSCs in vascular injury. Biomaterials 34(8), 1987-1994 (2013).

30 Yarmolenko PS, Moon EJ, Landon C et al. Thresholds for thermal damage to normal tissues: an update. Int. J. Hyperthermia 27(4), 320-343 (2011).

31 Alberts B, Johnson A, Lewis J, Raff M, Roberts K, Walter P. In: Molecular Biology of the Cell (4th Edition). Garland Science, NY, USA (2002).

32 Burattini S, Falcieri E. Analysis of cell death by electron microscopy. Meth. Mol. Biol. 1004, 77-89 (2013).

33 Coleman ML, Sahai EA, Yeo M, Bosch M, Dewar A, Olson MF. Membrane blebbing during apoptosis results from caspase-mediated activation of ROCK I. Nat. Cell Biol. 3(4), 339-345 (2001).

34 Bowen ID, Bowden SM. In: Programmed Cell Death in Tumours and Tissues. Springer, The Netherlands (1990).

35 Wright A, Bubb WA, Hawkins CL, Davies MJ. Singlet oxygen-mediated protein oxidation: evidence for the formation of reactive side chain peroxides on tyrosine residues. Photochem. Photobiol. 76(1), 35-46 (2002).

36 Sugden JK. Photochemistry of dyes and fluorochromes used in biology and medicine: some physicochemical background and current applications. Biotech. Histochem. 79(2), 71-90 (2004).

37 Rabin Y. Is intracellular hyperthermia superior to extracellular hyperthermia in the thermal sense? Int. J. Hyperthermia 18(3), 194-202 (2002). 